\title{
Quantification of alpha-amanitin in biological samples by HPLC using simultaneous UV- diode array and electrochemical detection
}

\author{
Juliana Garcia ${ }^{a}, *$, Vera M. Costa ${ }^{a}$, Paula Baptista ${ }^{\mathrm{b}}$, Maria de Lourdes Bastos ${ }^{\mathrm{a}}$, \\ Félix Carvalho ${ }^{\mathrm{a}, *}$ \\ ${ }^{\text {a } R E Q U I M T E / L a b o r a t o r y ~ o f ~ T o x i c o l o g y, ~ D e p a r t m e n t ~ o f ~ B i o l o g i c a l ~ S c i e n c e s, ~ F a c u l t y ~ o f ~ P h a r m a c y, ~ U n i v e r s i t y ~ o f ~ P o r t o, ~ R u a ~ J o s e ́ ~ V i t e r b o ~ F e r r e i r a ~} n^{\circ} 228$, \\ 4050-313 Porto, Portugal \\ ${ }^{\mathrm{b}}$ CIMO/School of Agriculture, Polytechnic Institute of Bragança, Campus de Santa Apolónia, Apartado 1172, 5301-854 Bragança, Portugal
}

\section{A R T I C L E I N F O}

\section{Article history:}

Received 6 November 2014

Received in revised form 27 May 2015

Accepted 4 June 2015

Available online 10 June 2015

\section{Keywords:}

High-performance liquid chromatographic

Diode-array

Electrochemical

$\alpha$-amanitin

\begin{abstract}
A B S T R A C T
$\alpha$-Amanitin is a natural bicyclic octapeptide, from the family of amatoxins, present in the deadly mushroom species Amanita phalloides. The toxicological and clinical interests raised by this toxin, require highly sensitive, accurate and reproducible quantification methods for pharmacokinetic studies. In the present work, a high-performance liquid chromatographic (HPLC) method with in-line connected diodearray (DAD) and electrochemical (EC) detection was developed and validated to quantify $\alpha$-amanitin in biological samples (namely liver and kidney). Sample pre-treatment consisted of a simple and unique deproteinization step with $5 \%$ perchloric acid followed by centrifugation at $16,000 \times \mathrm{g}, 4^{\circ} \mathrm{C}$, for $20 \mathrm{~min}$. The high recovery found for $\alpha$-amanitin ( $\geq 96.8 \%$ ) makes this procedure suitable for extracting $\alpha$-amanitin from liver and kidney homogenates. The resulting supernatant was collected and injected into the HPLC. Mobile phase was composed by $20 \%$ methanol in $50 \mathrm{mM}$ citric acid, and $0.46 \mathrm{mM}$ octanessulfonic acid, adjusted to $\mathrm{pH}$ 5.5. The chromatographic runs took less than $22 \mathrm{~min}$ and no significant endogenous interferences were observed at the $\alpha$-amanitin retention time. Calibration curves were linear with regression coefficients higher than 0.994 . The overall inter- and intra-assay precision did not exceed $15.3 \%$.

The present method has low interferences with simple and fast processing steps, being a suitable procedure to support in vivo toxicokinetic studies involving $\alpha$-amanitin. In fact, the validated method was successfully applied to quantify $\alpha$-amanitin in biological samples following intraperitoneal $\alpha$-amanitin administration to rats. Moreover, human plasma was also used as matrix and the purposed method was adequate for detection of $\alpha$-amanitin in that matrix. The results clearly indicate that the proposed method is suitable to investigate the pharmacokinetic and tissue distribution of $\alpha$-amanitin. Additionally, the method will be very useful in the development of novel and potent antidotes against amatoxins poisoning and to improve the knowledge of $\alpha$-amanitin toxicity.
\end{abstract}

(c) 2015 Elsevier B.V. All rights reserved.

\section{Introduction}

The main toxin of the amatoxins group, $\alpha$-amanitin (Fig. 1) is a toxic bicyclic octapeptide present in the deadly mushroom species Amanita phalloides. It represents up to $40 \%$ of the amatoxins present

Abbreviations: HPLC, high-performance liquid chromatography; DAD, diodearray; EC, electrochemical; DNA, deoxyribonucleic acid; LOD, limit of detection; LOQ limit of quantification; LC, liquid chromatography; MS, mass spectrometry; RNA, ribonucleic acid; RNAP II, RNA polymerase II; RSD, relative standard deviation; SPE, solid phase extraction; UV, ultraviolet.

* Corresponding authors. Fax: +35122609339.

E-mail addresses: jugarcia_18@hotmail.com (J. Garcia),felixdc@ff.up.pt (F. Carvalho). in this mushroom and is the main responsible for its toxic effects [1]. $\alpha$-Amanitin produces hepatic and kidney failure, which result in a potentially fatal outcome in most of the human intoxication cases [2]. The underlying toxicity mechanisms of $\alpha$-amanitin are not completely understood, but it is well accepted that the inhibition of RNA polymerase II (RNAP II) is its main effect [3] . Other mechanisms also appear to be involved, including oxidative stress [4].

So far, there is no specific and totally effective antidote against $A$. phalloides poisoning. Benzylpenicillin, ceftazidime, $\mathrm{N}-$ acetylcysteine, and silybin are the most extensively used antidotes, however mortality remains high [5]. Currently, in vivo and in silico studies are ongoing in search of effective antidotes, either directed to the toxicokinetics or to the toxicodynamics of amatoxins [6-9] 


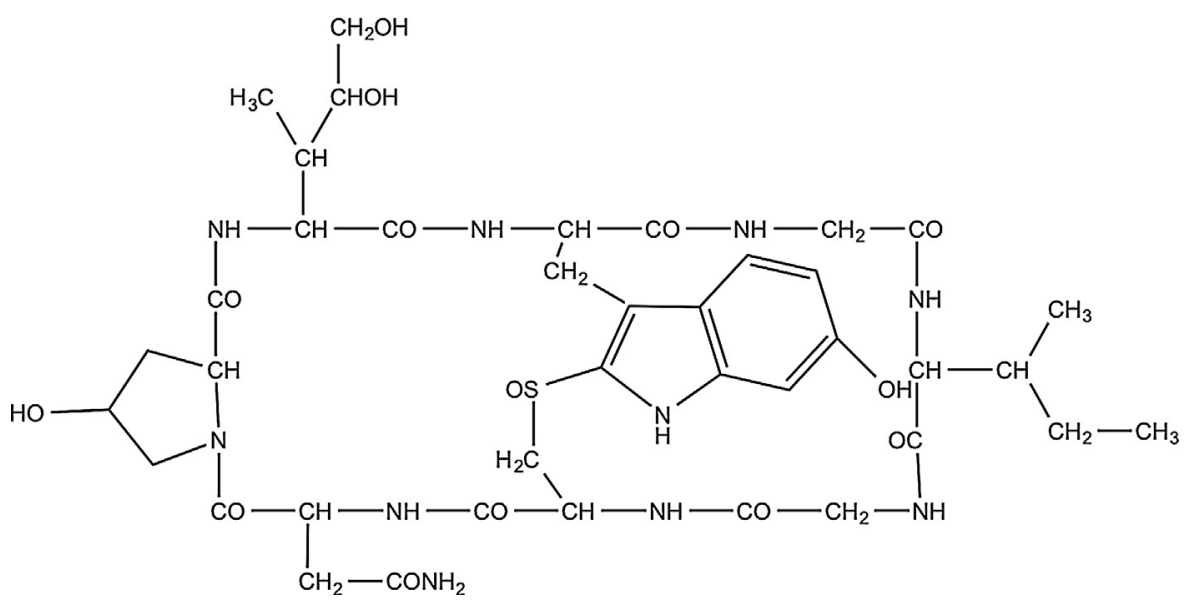

Fig. 1. Chemical structure of $\alpha$-amanitin.

. In both approaches, it is expected that the development of more insightful analytical and physiological methodologies will provide essential tools for achieving this purpose.

Besides the toxicological interest in $\alpha$-amanitin, recent findings indicate that $\alpha$-amanitin is emerging as an attractive new class of potent anticancer drug [10]. For this clinical application, adequate analytical methodologies are also required for the evaluation of $\alpha$-amanitin pharmacokinetics, both in pre-clinical and clinical studies.

The comprehensive characterization of antidotes in A. phalloides poisoning and the pharmacokinetics and toxicokinetic studies of $\alpha$-amanitin require highly sensitive, accurate and reproducible quantification assays. Currently, there are several high-performance liquid chromatography (HPLC)-ultraviolet (UV) [11-17], liquid chromatography (LC)-mass spectrometry (MS) [18-20] and ultra performance liquid chromatography (UPLC)MS/MS [21] methods to determine $\alpha$-amanitin in mushrooms, liver and biological fluids (Table 1). HPLC-MS methods for $\alpha$-amanitin detection are accurate, sensitive, and specific; nevertheless HPLCMS is an expensive technique and is not available in many laboratories. To date there are no published HPLC with electrochemical (EC) detection methods for the analysis of $\alpha$-amanitin in biological tissues. Hence, in this paper, we describe a simple acidic extraction and HPLC methodology with in-line connected photodiode array detection (DAD) and EC detection to quantify $\alpha$-amanitin in rat liver and kidney. Moreover, we applied the validated method to identify $\alpha$-amanitin in human plasma. The validated method was successfully applied to quantify $\alpha$-amanitin in plasma, liver and kidney tissues following intraperitoneal administration to rats. The new method provides the required high analytical sensitivity and reproducibility, with a simple and fast pretreatment, as it is required for advanced pharmacokinetic and toxicokinetic research.

\section{Material and methods}

\subsection{Reagents and chemicals}

$\alpha$-Amanitin (>99\%), bovine serum albumin, and 1octanesulfonic acid sodium salt were purchased from Sigma-Aldrich (St. Louis, MO, USA). Analytical HPLC grade methanol was obtained from Fisher Scientific (Waltham, Massachusetts, USA). Sodium chloride $(\mathrm{NaCl})$, potassium chloride $(\mathrm{KCl})$, sodium hydrogen phosphate $\left(\mathrm{Na}_{2} \mathrm{HPO}_{4}\right)$, potassium dihydrogen phosphate $\left(\mathrm{KH}_{2} \mathrm{PO}_{4}\right)$ and $60 \%(\mathrm{~m} / \mathrm{v})$ perchloric acid were purchased from Merck (Darmstadt, Germany). Water was purified with a Milli-Q Plus ultra-pure water purification system (Millipore, Bedford, Massachusetts, USA).

\subsection{Chromatographic conditions}

HPLC analysis was performed using a Waters 2690 separation module (Waters, Milford, MA, USA), and a $250 \mathrm{~mm} \times 4.6 \mathrm{~mm}$, Waters Spherisorb RP-18 (5 $\mu \mathrm{m})$ ODS2 column. The mobile phase (20\% methanol in $50 \mathrm{mM}$ citric acid, $0.46 \mathrm{mM}$ octanessulfonic acid, adjusted to $\mathrm{pH} 5.5$ with $10 \mathrm{M} \mathrm{NaOH}$ ) was filtered through a $0.45 \mu \mathrm{m}$ membrane (Millipore, Madrid, Spain) and degassed. An isocratic elution was performed at a flow rate of $1.0 \mathrm{~mL} / \mathrm{min}$, at room temperature. Sample aliquots of $20 \mu \mathrm{L}$ were injected. A Compaq computer fitted with Millenium32 software (Waters) processed the chromatographic and spectral data.

For the spectroscopic and coulochemical analysis, a photodiode array detector (Waters model 996) and/or a Colouchem II (ESA, Chelmsford, USA) equipped with a guard cell (ESA 5020) and analytical cell (ESA 5011A) electrochemical detector were used. In all the studies, both detectors were used, with the analytical cell of the coulochemical detector placed after the photodiode array detector. The electrochemical potential settings of Coulochem II detector were: guard cell, $-550 \mathrm{mV}$, and analytical detector + $500 \mathrm{mV}$, following a previous reported procedure [22]. A current of $5 \mu \mathrm{A}$ full-scale was used. Ultraviolet-visible spectra were collected for all samples between from 230 to $400 \mathrm{~nm}$. For quantitative analyses, chromatograms were integrated at $305 \mathrm{~nm}$ [15].

\subsection{Stock solution and calibration standards}

A stock solution of $\alpha$-amanitin was prepared in water Milli-Q and diluted to a final concentration of $1 \mathrm{mg} \mathrm{mL}^{-1}$. All stock solutions were stored of $-20^{\circ} \mathrm{C}$. A set of eleven standards ranging from

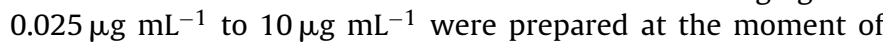
use by spiking the rat liver and kidney samples with appropriate amounts of $\alpha$-amanitin. All calibration standards were prepared in triplicate.

\subsection{Animals and sample preparation}

The liver and kidney tissues were obtained from adult male Wistar rats. These animals were used as healthy controls in other experiments, where liver and kidney were not necessary. A minimum number of animals was used in order to obtain valid results. All experiments were approved by local ethical committee. All rats were between 5 and 6 weeks of age and weighting about 150 to 
Table 1

Liquid chromatographic methods for $\alpha$ - amanitin analysis in different matrices.

\begin{tabular}{|c|c|c|c|c|c|c|}
\hline \multirow[b]{2}{*}{ Method } & \multirow[b]{2}{*}{ Matrix } & \multicolumn{2}{|l|}{ LOD } & \multicolumn{2}{|l|}{ LOQ } & \multirow[b]{2}{*}{ References } \\
\hline & & $\mathrm{ng} \mathrm{mL}^{-1}$ & $\mathrm{ng} \mathrm{g}^{-1}$ & $\mathrm{ng} \mathrm{mL} L^{-1}$ & $\mathrm{ng} \mathrm{g}^{-1}$ & \\
\hline HPLC-UV & Mushrooms & 10 & & ns & & [15] \\
\hline HPLC-UV & Serum & 6 & & 3 & & [31] \\
\hline \multirow[t]{5}{*}{ HPLC-UV } & Plasma & 5 & & & & [29] \\
\hline & Urine & 5 & & & & \\
\hline & $\begin{array}{l}\text { Gastroduodenal } \\
\text { fluid }\end{array}$ & 5 & & & & \\
\hline & Liver & 5 & & & & \\
\hline & Kidney & 5 & & & & \\
\hline \multirow[t]{3}{*}{ HPLC-UV } & Serum & 10 & & ns & & [16] \\
\hline & Urine & 10 & & ns & & \\
\hline & Stomach washings & 10 & & ns & & \\
\hline \multirow[t]{2}{*}{ LC-MS/MS/MS } & Serum & & 0.26 & ns & & [19] \\
\hline & Liver & & 0.5 & ns & & \\
\hline HPLC-EC & Urine & 2 & & 10 & & {$[22]$} \\
\hline LC-MS/MS & Plasma & 0.5 & & ns & & [20] \\
\hline LC-MS/MS & Mushrooms & & 20 & & 15.1 & [18] \\
\hline HPLC-EC & Plasma & 2 & & ns & & [28] \\
\hline LC-MS & Urine & 2.5 & & 5 & & [32] \\
\hline \multirow{2}{*}{ UPLC-MS/MS } & Urine & 0.22 & & 0.46 & & [21] \\
\hline & Liver & & 10.9 & & 14.7 & \\
\hline
\end{tabular}

ns: not specified.

200 g. Rats were sacrificed by guillotine decapitation by an experienced veterinarian and liver and kidney tissues were immediately collected and kept frozen at $-20^{\circ} \mathrm{C}$ until homogenization. One gram of each organ was homogenized using an Ultra-Turrax homogenizer in $4 \mathrm{~mL}$ of $0.1 \mathrm{M}$ phosphate buffer, $\mathrm{pH}$ 7.4. The homogenate was placed in perchloric acid ( $5 \%$ final concentration) in the ratio $1: 2$ for protein denaturation, and centrifuged at $16,000 \times \mathrm{g}, 4^{\circ} \mathrm{C}$ for $20 \mathrm{~min}$. The resulting supernatant was collected and injected into the HPLC before or after spiking with $\alpha$-amanitin, depending on the condition to be tested.

\subsection{Method validation}

The HPLC method with simultaneous DAD and EC detection for the determination of $\alpha$-amanitin in $5 \%$ perchloric acid, and in liver and kidney samples was validated by the evaluation of the following parameters: specificity, linearity, recovery, precision, sensitivity, matrix effect and analyte stability.

\subsubsection{Specificity}

Specificity is the ability to assess unequivocally the analyte in the presence of components that may be expected to be present in that matrix [23]. Specificity of the method was tested by analysis of three different blanks: 5\% perchloric acid, rat liver and kidney extracts and compared to samples spiked with $5 \mu \mathrm{g} \mathrm{mL}^{-1}$ of $\alpha$-amanitin to ensure the absence of compounds with similar retention times. The purity of the peak of $\alpha$-amanitin was investigated by determining the ultraviolet and visible spectrum with maximum absorbance using the DAD and by comparing the retention times between spiked samples and pure controls.

\subsubsection{Linearity}

The linearity of an analytical procedure is its ability to obtain test results that are directly proportional to the concentration of analyte in the sample within a given range [23]. The linearity response for $\alpha$-amanitin was initially studied using eleven standards in $5 \%$ perchloric acid injected three times, covering the range of $0.025-10 \mu \mathrm{g} \mathrm{mL}^{-1}$. Subsequently, linearity was studied in biological samples spiked with a series of $\alpha$-amanitin standards covering the mentioned range. The linearity was evaluated by linear regression analysis.

\subsubsection{Recovery}

Typically, the accuracy of the analytical methods is determined by recovery studies done by spiking the blank matrix with the analyte prior to sample treatment [24]. Therefore, recovery was used to further evaluate the accuracy of the method in our study. To determine method accuracy, different concentrations of $\alpha$-amanitin (low, medium and high) were used to spike blank liver and kidney samples $(n=3)$. After homogenization, known concentrations of $\alpha$-amanitin were added to three different rat liver and kidney preparations placed in $0.1 \mathrm{M}$ phosphate buffer. The final hepatic homogenate concentrations used to assess low, medium and high concentrations were: $0.5,5$, and $7.5 \mu \mathrm{g} \mathrm{mL}^{-1}$ of $\alpha$-amanitin. The final renal homogenate concentrations used to assess low, medium and high concentrations were: $0.82,5$, and $7.5 \mu \mathrm{g} \mathrm{mL}-1$ of $\alpha-$ amanitin. After vortexing for $1 \mathrm{~min}$, the homogenates were placed in perchloric acid ( $5 \%$ final concentration). Centrifugation followed for $10 \mathrm{~min}$ at $16,000 \times \mathrm{g}$, the supernatants being collected and injected in the HPLC. The recoveries were assessed by comparing the peak area of the $\alpha$-amanitin extracted from liver and kidney homogenates to those of blank deproteinized liver and kidney samples spiked with similar concentrations and injected in the same day and HPLC conditions.

\subsubsection{Precision}

Precision expresses the degree of scatter between a series of measurements obtained from multiple sampling of the same homogeneous sample. Precision may be considered at three levels: repeatability, intermediate precision, and reproducibility [23]. In this work, method precision (intra-assay repeatability), instrument precision (injection repeatability), and intermediate precision were investigated. To determine method precision (intra-assay), different concentrations of $\alpha$-amanitin (low, middle and high) were used by spiking blank hepatic and renal samples and performing several replicates $(n=6)$. Known concentrations of $\alpha$-amanitin were added to biological matrices to obtain final liver matrix concentrations of 0.5 (low), 5 (medium) and $7.5 \mu \mathrm{g} \mathrm{mL}^{-1}$ (high) and kidney matrix concentrations of 0.82 (low), 5 (medium) and $7.5 \mu \mathrm{g} \mathrm{mL}^{-1}$ (high). The samples were analyzed by the same analyst and in the same 
day. Intermediate precision was also studied in order to determine the agreement of the measurements when the method was used on different days. The inter-assay precision was determined by the analysis of the same concentrations of $\alpha$-amanitin used in the intraassay study through the injection of six replicates on three different days over a period of three weeks. The precision was reported as the relative standard deviation (\% RSD). The\% RSD of the proposed method was calculated using the following equation: \% RSD $=S / x$ where $S$ is the standard deviation and $x$ is the mean of response.

\subsubsection{Sensitivity}

The limit of detection (LOD) of an analytical procedure is the lowest concentration of an analyte in a sample, which can be detected but not necessarily quantitated as an exact value. The limit of quantification (LOQ) is the lowest amount of analyte in a sample that can be quantitatively determined with suitable precision and accuracy [23]. The LOD and LOQ were calculated by using standard solutions prepared in 5\% perchloric acid, liver and kidney samples. Two different criteria were applied. Firstly, the LOD and LOQ were measured based on visual evaluation according to International Conference on Harmonization Q2 (ICH Q2) guidelines [25], by successively diluting a stock solution containing $1 \mathrm{mg} \mathrm{mL}^{-1}$ of $\alpha$-amanitin. The minimum concentrations of $\alpha$-amanitin that were reliably detected and quantified with acceptable accuracy and precision were considered the LOD and LOQ of our method, respectively. Additionally, the LOD and LOQ were determined using the calibration curve method described in the same guidelines [25]. The LOD $(k=3.3)$ and LOQ $(k=10)$ were calculated using the following equation: $A=k \sigma / S$, where A is LOD or LOQ $\sigma$ is the standard deviation of the response, and $S$ is the slope of the calibration curve.

\subsubsection{Evaluation of the matrix effect}

The matrix effect was evaluated by comparing the calibration graphs obtained by spiking liver and kidney samples with known amounts of $\alpha$-amanitin, and the calibration graph was obtained from standard $\alpha$-amanitin 5\% perchloric acid solutions.

\subsubsection{Analyte stability}

A stability study was performed in order to assess the stability of the analyte, in different storage and analysis conditions. $\alpha$-Amanitin stability experiments' were evaluated in 5\% perchloric acid, and in deproteinized liver and kidney samples. Perchloric acid (5\%) and blank liver and kidney samples were divided into four aliquots, and each aliquot was spiked with $\alpha$-amanitin at $2.5 \mu \mathrm{g} \mathrm{mL} \mathrm{m}^{-1}$. Final concentration of each sample was analyzed immediately, while the remaining samples were stored at room temperature, $4^{\circ} \mathrm{C},-20^{\circ} \mathrm{C}$ and $-80^{\circ} \mathrm{C}$ and thereafter analyzed after $24 \mathrm{~h}, 7,14$ days without any other freeze-thaw cycles.

Stability was also studied after several freeze-thaw cycles. Perchloric acid (5\%), blank liver and kidney samples were divided into two aliquots, each aliquot was spiked with $\alpha$-amanitin at $2.5 \mu \mathrm{g} \mathrm{mL} \mathrm{m}^{-1}$ and stored at $-20^{\circ} \mathrm{C}$ and $-80^{\circ} \mathrm{C}$. These samples were analyzed after three freeze-thaw cycles at room temperature. All samples used for stability testing were tested in triplicate. A standard curve was constructed during each analytical evaluation and injected in the same day and conditions.

\subsection{Method application}

The described analytical method was applied to four different human plasma samples. Aliquots of these plasma samples were spiked with $\alpha$-amanitin to a final concentration of $5 \mu \mathrm{g} \mathrm{mL} L^{-1}$ followed by deproteinization using perchloric acid (5\% final concentration). The dispersion was vortexed for $1 \mathrm{~min}$ and then the samples were centrifuged at $16,000 \times \mathrm{g}$ for $10 \mathrm{~min}$ at $4^{\circ} \mathrm{C}$. The supernatants were then collected and injected into the HPLC system.

\subsection{In vivo validation of the method}

Female Wistar rats were used as the animal model for in vivo experiments. Animals were obtained from vivarium of Institute of Biomedical Sciences - ICBAS, University of Porto and were between 120 and $150 \mathrm{~g}$ at the time of experiment. The protocol was approved by the local committee for the welfare of experimental animals and was performed in accordance with national legislation. Rats received $\alpha$-amanitin (dissolved in saline solution) intraperitoneally at a dose of $10 \mathrm{mg} \mathrm{kg}^{-1}$ and $21.4 \mathrm{mg} \mathrm{kg}^{-1}$ for different time-points. After two or four hours, the animals were anesthetized with isoflurane and sacrificed by exsanguination, collecting the blood in the inferior vena cava into EDTA- containing tubes. Plasma was isolated from blood by centrifugation at $920 \times \mathrm{g}$ for $10 \mathrm{~min}$ at $4{ }^{\circ} \mathrm{C}$. Liver and kidneys were removed, weighed, and homogenized in ice-cold $0.1 \mathrm{M}$ phosphate buffer, $\mathrm{pH}$ 7.4. An aliquot of the homogenate was stored $\left(-20^{\circ} \mathrm{C}\right)$ for posterior protein quantification. An aliquot of the homogenate was placed in perchloric acid ( $5 \%$ final concentration) for protein denaturation, and centrifuged at $16,000 \times \mathrm{g}, 4^{\circ} \mathrm{C}$ for $20 \mathrm{~min}$. The supernatant was then collected and injected into the HPLC system. A set of eleven standards ranging from $0.025 \mu \mathrm{g} \mathrm{mL}^{-1}$ to $10 \mu \mathrm{g} \mathrm{mL}^{-1}$ were prepared at the moment of use by spiking rat liver and kidney samples with appropriate amounts of $\alpha$-amanitin, as described before. The $\alpha$-amanitin levels in plasma, liver and kidney at 2 and $4 \mathrm{~h}$ after administration were determined. As to confirm the identity of the $\alpha$-amanitin peak, samples were spiked with a standard solution of $5 \mu \mathrm{g} \mathrm{mL} \mathrm{m}^{-1}$ of $\alpha$-amanitin.

\subsubsection{Protein determination}

Protein content was determined by the method described by Lowry [26]. Bovine serum albumin was used as protein standard. Fifty $\mu \mathrm{L}$ of samples, standards or blank were added in triplicate to a 96-well microtiter plate, followed by addition $100 \mu \mathrm{L}$ of extemporaneously prepared Reagent A $(9.8 \mathrm{~mL}$ of $2 \%$ sodium carbonate, $100 \mu \mathrm{L}$ of $2 \%$ sodium potassium tartrate and $100 \mu \mathrm{L}$ of $1 \%$ sulfate cupper II). After $10 \mathrm{~min}$ under light protection, $100 \mu \mathrm{L}$ of extemporaneously prepared Reagent B (Folin-Ciocalteu reagent and $\mathrm{H}_{2} \mathrm{O}$, $1: 14)$ was added. The microtiter plate was kept protected from the light for $20 \mathrm{~min}$, after which the absorbance was measured at $750 \mathrm{~nm}$.

\subsection{Statistical analysis}

The linearity was evaluated by the linear regression test. Evaluation of the matrix effect was performed by one-way analysis of variance to determine the statistical significance between the slopes of the $5 \%$ perchloric acid, liver and kidney standard calibration curves. Statistical significance was set at $p<0.05$. The Tukey multiple comparisons test was used once a significant $p$ was achieved. In the evaluation of stability, different conditions were assessed in different time-points, thus a two-way analysis of variance was performed. If a statistical significant effect was found $(p<0.05)$, the Tukey multiple comparisons test was performed. All statistical tests were performed using GraphPad Prism version 6 (San Diego, California, USA).

\section{Results}

\subsection{Optimization of the chromatographic conditions}

In order to obtain low background noise in the biological matrices, citric acid/methanol was used as mobile phase, as citrate can be 


\section{Absorbance at $305 \mathrm{~nm}$}

A

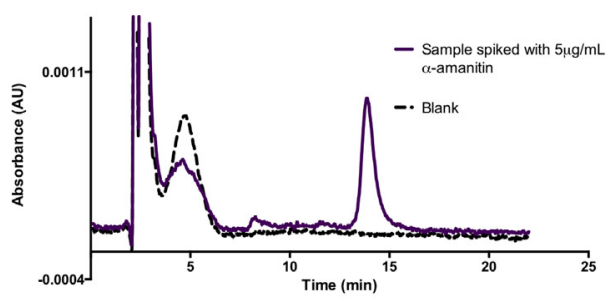

C

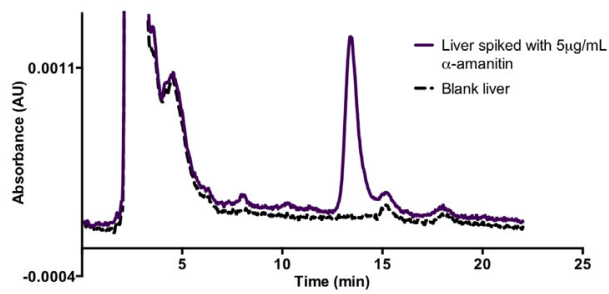

$\mathbf{E}$

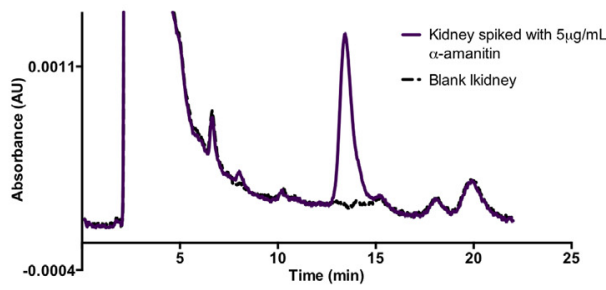

Electrochemical detection

B

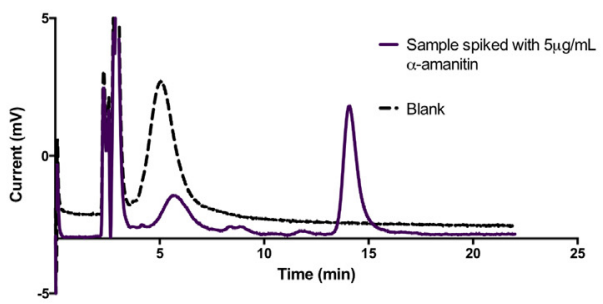

D

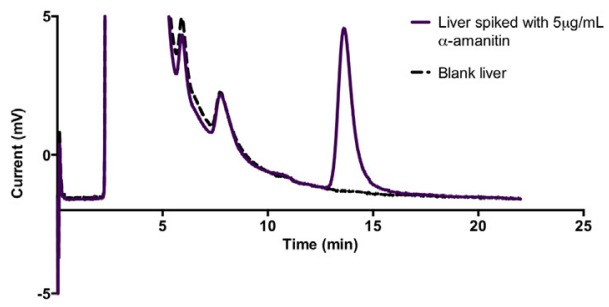

F

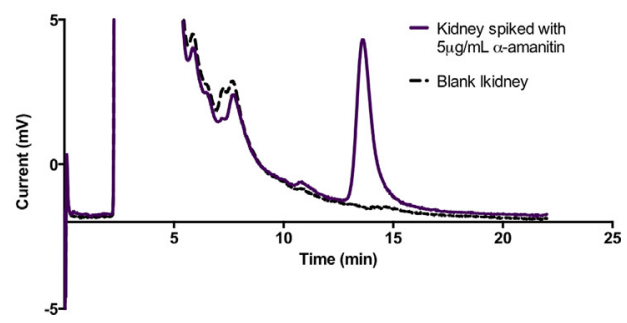

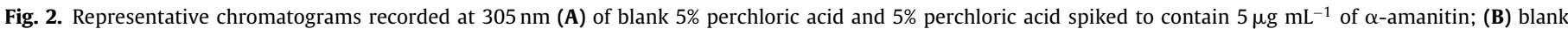

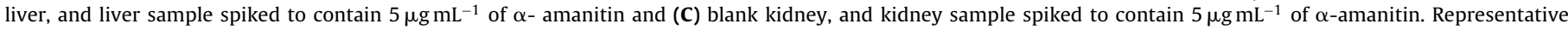

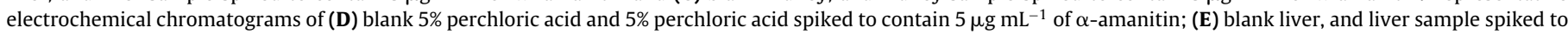
contain $5 \mu \mathrm{g} \mathrm{mL} \mathrm{m}^{-1}$ of $\alpha$ - amanitin and (F) blank kidney, and kidney sample spiked to contain $5 \mu \mathrm{g} \mathrm{mL}-1$ of $\alpha$ - amanitin.

used in a wide range of $\mathrm{pH}(2.1<\mathrm{pH}<6.4)$ and provides low background noise $[24,27]$. It was observed that the ratio of citric acid and methanol (80:20) was key to a good separation and resolution of the peaks. The $\mathrm{pH}$ value was also studied as it has an important role in the resolution of complex mixtures as homogenates. Thus it is also important to properly adjust the $\mathrm{pH}$ of the mobile phase. For this purpose, a pH of 5.5 was chosen, since it gave the best chromatographic resolution and the sharpest peaks. Moreover, the octanessulfonic acid, an ion pairing reagent, leads to an enhanced resolution of the $\alpha$-amanitin peak. Taken together, the optimization of the mobile phase and $\mathrm{pH}$ led to an optimal chromatographic resolution of the sample components and a low chromatographical run (22 min) (Fig. 2).

\subsection{Sample preparation}

The main goal of the sample preparation was to create a simple method that allowed the elimination of interferences and good stability of the analyte, $\alpha$-amanitin. Liver and kidney are quite complex matrices, with high level of proteins, thus, a good deproteinizing step was required. For this purpose, we used perchloric acid (5\% final concentration). After centrifugation, the resulting supernatant can be directly injected into HPLC, therefore resulting in a simple procedure that can be performed in all laboratory settings.

\subsection{Method validation}

\subsubsection{Specificity}

The specificity of the assay was examined using the described chromatographic conditions on Section 2. Representative chromatograms recorded at $305 \mathrm{~nm}$ of blank $5 \%$ perchloric acid and a $5 \%$ perchloric acid spiked to contain $5 \mu \mathrm{g} \mathrm{mL}^{-1}$ of $\alpha$-amanitin (Fig. 2A), blank liver sample and a liver sample spiked to contain $5 \mu \mathrm{g} \mathrm{mL}^{-1}$ of $\alpha$ - amanitin (Fig. 2C) and a blank kidney sample and a kidney sample spiked to contain $5 \mu \mathrm{g} \mathrm{mL}-1$ of $\alpha$-amanitin (Fig. 2E) are shown in Fig. 2. Representative electrochemical (EC) chromatograms of blank $5 \%$ perchloric acid and a perchloric acid spiked to contain $5 \mu \mathrm{g}$ $\mathrm{mL}^{-1}$ of $\alpha$-amanitin (Fig. 2B), blank liver sample and a liver sample spiked to contain $5 \mu \mathrm{g} \mathrm{mL-1}$ of $\alpha$-amanitin (Fig. 2D) and a blank kidney sample and a kidney sample spiked to contain $5 \mu \mathrm{g} \mathrm{mL}-1$ of $\alpha$-amanitin (Fig. 2F) are also shown. There were no endogenous interfering substances in the samples at the same retention time of $\alpha$-amanitin.

\subsubsection{Linearity}

The linear least squares regression equation (1/c2) correlation coefficients of the standard curves for $\alpha$-amanitin in 5\% perchloric acid, and for liver and kidney extracts were all above 0.994 . The linear equations and corresponding coefficient of determination $\left(r^{2}\right)$ 
Table 2

Linearity data of $\alpha$-amanitin analysis in 5\% perchloric acid and tissue samples.

\begin{tabular}{|c|c|c|c|c|c|}
\hline & Linear equation & Slope $( \pm$ SD $)$ & Intercept $( \pm \mathrm{SD})$ & Determination coeficiente $\left(r^{2}\right)$ & Linear range $\left(\mu \mathrm{g} \mathrm{mL}^{-1}\right)$ \\
\hline \multicolumn{6}{|l|}{$305 \mathrm{~nm}$} \\
\hline Perchloric acid 5\% & $y=9677 x-910.8$ & $9677 \pm 121.1$ & $-910.8 \pm 556.9$ & 0.9964 & $0.45-10$ \\
\hline Liver & $y=9279 x+432.2$ & $9279 \pm 87.21$ & $432.2 \pm 381.8$ & 0.9983 & $0.33-10$ \\
\hline Kidney & $y=6858 x+2404$ & $6858 \pm 54.21$ & $2404 \pm 256.3$ & 0.9990 & $0.5-10$ \\
\hline \multicolumn{6}{|c|}{ Electrochemical detection } \\
\hline Perchloric acid 5\% & $y=54,113 x-4772$ & $53759 \pm 931.4$ & $-4772 \pm 3814$ & 0.9935 & $0.19-10$ \\
\hline Liver & $y=54,260 x+77.95$ & $54260 \pm 674.8$ & $77.95 \pm 2763$ & 0.9966 & $0.21-10$ \\
\hline Kidney & $y=42,409 x+951.0$ & $42409 \pm 426.4$ & $951 \pm 1646$ & 0.9975 & $0.11-10$ \\
\hline
\end{tabular}

Absorbance at $305 \mathrm{~nm}$

A

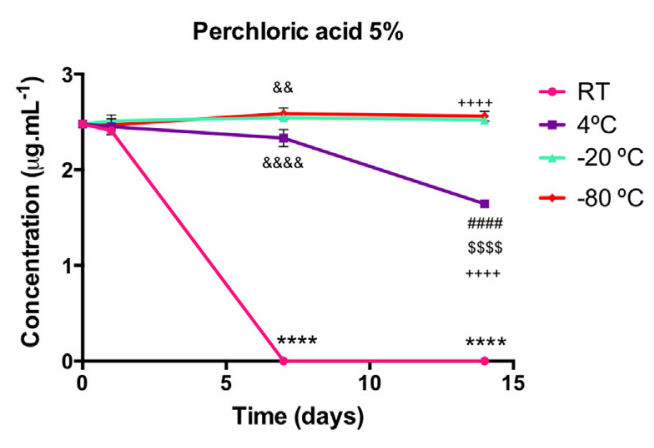

C

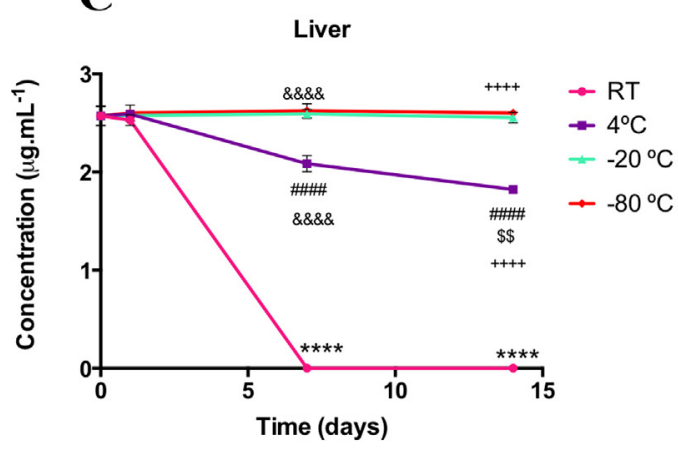

E

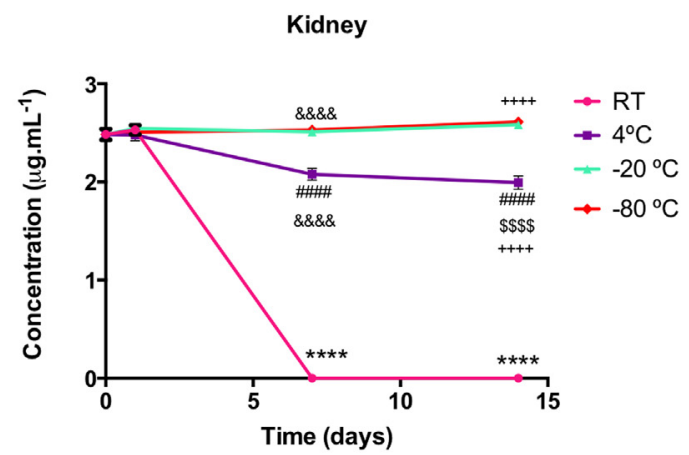

\section{Electrochemical detection}

B

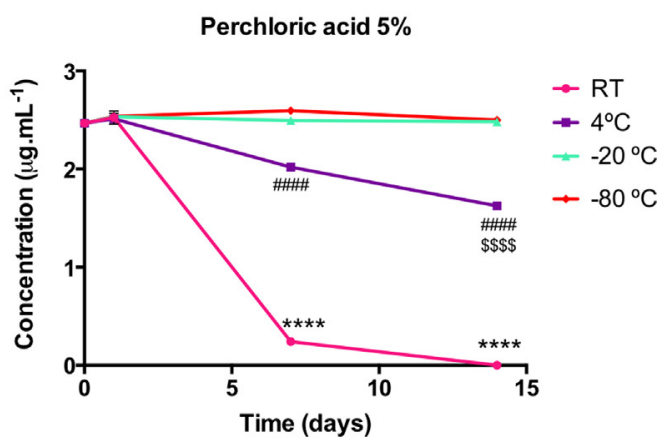

D

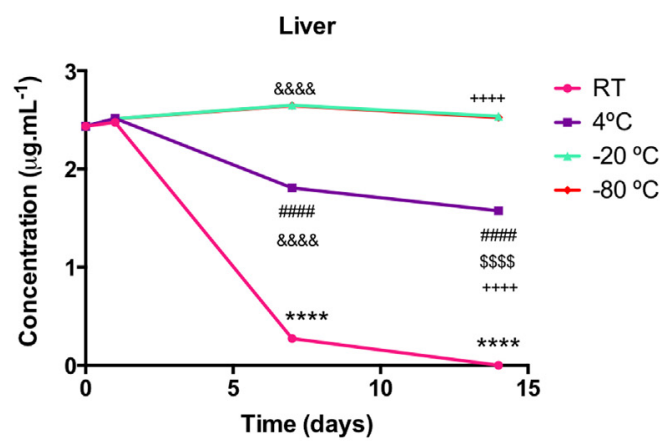

F

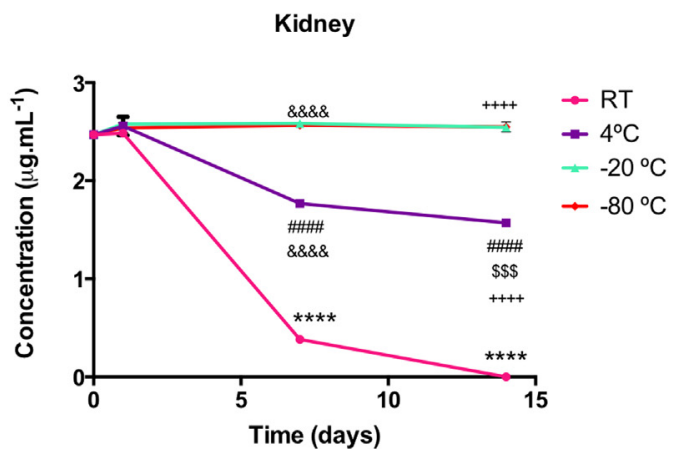

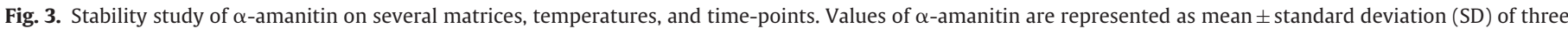

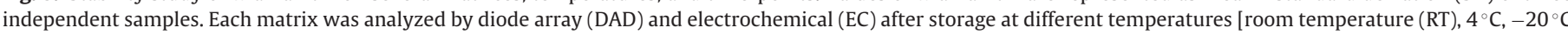

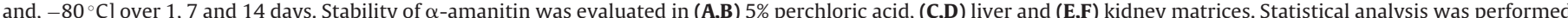

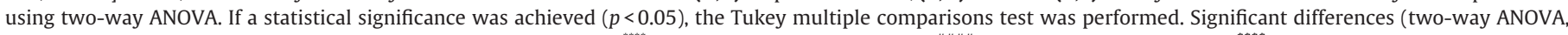

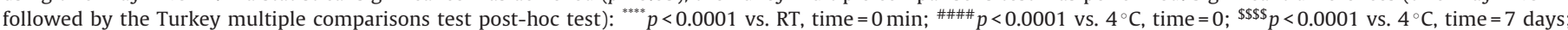

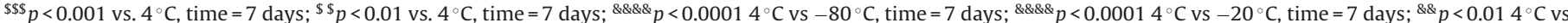
$-20{ }^{\circ} \mathrm{C}$, time $=7$ days; ${ }^{++++} p<0.00014{ }^{\circ} \mathrm{C}$ vs $-80{ }^{\circ} \mathrm{C}$, time $=14$ days; ${ }^{++++} p<0.00014{ }^{\circ} \mathrm{C}$ vs $-20{ }^{\circ} \mathrm{C}$, time $=14$ days 
Table 3

Precision and accuracy results.

\begin{tabular}{|c|c|c|c|c|}
\hline$\alpha$-amanitin $\left(\mu \mathrm{g} \mathrm{mL}^{-1}\right)$ & $\begin{array}{l}\text { Intra-assay precision } \\
\operatorname{RSD}^{\mathrm{a}}(\%)(n=6)\end{array}$ & $\begin{array}{l}\text { Inter-assay precision } \\
\operatorname{RSD}^{\mathrm{a}}(\%)(n=18)\end{array}$ & Recovery (\%) & $\operatorname{RSD}(\%)(n=3)$ \\
\hline \multicolumn{5}{|l|}{$305 \mathrm{~nm}$} \\
\hline \multicolumn{5}{|l|}{ Perchloric acid 5\% } \\
\hline 0.84 & 2.75 & 6.10 & & \\
\hline 5 & 1.15 & 5.57 & & \\
\hline 7.5 & 1.65 & 5.66 & & \\
\hline \multicolumn{5}{|l|}{ Liver } \\
\hline 0.5 & 8.65 & 15.30 & 99.99 & 2.49 \\
\hline 5 & 3.97 & 4.27 & 98.48 & 2.00 \\
\hline 7.5 & 0.61 & 3.54 & 99.89 & 0.21 \\
\hline \multicolumn{5}{|l|}{ Kidney } \\
\hline 0.82 & 8.16 & 11.59 & 101.06 & 2.13 \\
\hline 5 & 2.18 & 6.30 & 99.42 & 1.05 \\
\hline 7.5 & 1.73 & 2.63 & 99.69 & 0.90 \\
\hline \multicolumn{5}{|c|}{ Electrochemical detection } \\
\hline \multicolumn{5}{|l|}{ Perchloric acid 5\% } \\
\hline 0.84 & 2.13 & 3.91 & & \\
\hline 5 & 2.64 & 5.22 & & \\
\hline 7.5 & 1.64 & 10.70 & & \\
\hline \multicolumn{5}{|l|}{ Liver } \\
\hline 0.5 & 2.27 & 7.49 & 99.87 & 3.41 \\
\hline 5 & 1.65 & 6.36 & 99.80 & 1.03 \\
\hline 7.5 & 0.55 & 9.72 & 96.87 & 3.21 \\
\hline \multicolumn{5}{|l|}{ Kidney } \\
\hline 0.82 & 3.87 & 10.94 & 99.49 & 1.99 \\
\hline 5 & 3.60 & 8.99 & 98.19 & 2.16 \\
\hline 7.5 & 2.43 & 6.64 & 101.45 & 2.62 \\
\hline
\end{tabular}

a Acceptance criteria: $\mathrm{RSD} \pm 20 \%$.

values for solutions of $\alpha$-amanitin in 5\% perchloric acid, liver and kidney matrices are shown in Table 2. All the linearity, range parameters, and their related validation data are shown in Table 2 . The regression data for calibration curve shows good linear relationship with $r^{2}>0.990$.

\subsubsection{Recovery}

Recovery from the spiked samples was determined as described in Section 2.5.3. Results show an overall mean percent recovery of above $96 \%$ (Table 3).

\subsubsection{Precision}

The repeatability and the intermediate precision (intra- and inter-assay precision) were calculated as the RSD of replicate samples at three concentration levels of $\alpha$-amanitin, as described in Section 2.5.4.

The intra- and inter-assay precision for detection of $\alpha$-amanitin in $5 \%$ perchloric acid, and rat liver and kidney matrices are presented in Table 3. As shown in Table 3, intra-assay precision for $5 \%$ perchloric acid matrix ranged from $1.15 \%$ to $2.75 \%$ (DAD) and $1.64 \%$ to $2.64 \%$ (EC) whereas the inter- assay precision ranged from $5.57 \%$ to $6.10 \%$ (DAD) and $3.91 \%$ to $10.70 \%$ (EC). Intra-assay precision for liver matrix ranged from $0.61 \%$ to $8.65 \%$ (DAD) and $0.55 \%$ to $2.27 \%$ (EC) whereas the inter-assay precision ranged from $3.54 \%$ to $15.30 \%$ (DAD) and $6.36 \%$ to $9.72 \%$ (EC). Finally, intra-assay precision for kidney matrix ranged from $1.73 \%$ to $8.16 \%$ (DAD) and $2.43 \%$ to $3.87 \%$ (EC) whereas the inter-assay precision ranged from $2.63 \%$ to $11.59 \%$ (DAD) and $6.64 \%$ to $10.94 \%$ (EC). Acceptable RSD values (lower than $20 \%$ ) were obtained for all concentration and for both detectors (DAD and EC), thus the developed method was sufficiently precise.

\section{Table 4}

LOD and LOQ values (expressed as $\mu \mathrm{g} \mathrm{mL}^{-1}$ or $\mu \mathrm{gg}^{-1}$ ) computed according to different criteria.

\begin{tabular}{llll}
\hline & $\begin{array}{l}\text { Perchloric acid 5\% } \\
\left(\mu \mathrm{gL}^{-1}\right)\end{array}$ & $\begin{array}{l}\text { Liver } \\
\left(\mu \mathrm{gg}^{-1}\right)\end{array}$ & $\begin{array}{l}\text { Kidney } \\
\left(\mu \mathrm{g} \mathrm{g}^{-1}\right)\end{array}$ \\
\hline $\mathbf{3 0 5} \mathbf{~ n m}$ & & & \\
$\begin{array}{l}\text { LOD } \\
\text { Calibration Curve }\end{array}$ & 0.150 & 0.110 & 0.160 \\
Based on visual evaluation & 0.050 & 0.050 & 0.125 \\
$\begin{array}{l}\text { LOQ } \\
\text { Calibration Curve }\end{array}$ & 0.450 & & \\
Based on visual evaluation & 0.250 & 0.330 & 0.500 \\
Electrochemical detection & & 0.250 & 0.330 \\
$\begin{array}{l}\text { LOD } \\
\text { Calibration Curve }\end{array}$ & 0.060 & & \\
Based on visual evaluation & 0.015 & 0.070 & 0.040 \\
LOQ & & 0.015 & 0.050 \\
Calibration Curve & 0.190 & & \\
Based on visual evaluation & 0.025 & 0.210 & 0.110 \\
\hline
\end{tabular}

\subsubsection{Sensitivity}

LOD and LOQ were evaluated and the obtained data are shown in Table 4. Based on visual evaluation, the LOD and LOQ values for $5 \%$ perchloric acid were 0.050 and $0.250 \mu \mathrm{g} \cdot \mathrm{g}^{-1}$ (DAD), and 0.015 and $0.025 \mu \mathrm{g} . \mathrm{g}^{-1}$ (EC), respectively. For liver matrix, the LOD and LOQ values were 0.050 and $0.250 \mu \mathrm{g}^{-g^{-1}}$ (DAD) and 0.015 and $0.025 \mu \mathrm{g} . \mathrm{g}^{-1}(\mathrm{EC})$, respectively. For kidney matrix the LOD

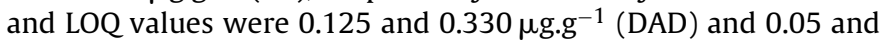
$0.100 \mu \mathrm{g} . \mathrm{g}^{-1}$ (EC), respectively. Based on the calibration curve, for $5 \%$ perchloric acid matrix, the LOD and LOQ values were 0.150 and $0.450 \mu \mathrm{g} . \mathrm{g}^{-1}$ (DAD) and 0.060 and $0.190 \mu \mathrm{g} . \mathrm{g}^{-1}$ (EC), respectively; for liver matrix the LOD and LOQ values were 0.110 and $0.330 \mu \mathrm{g} . \mathrm{g}^{-1}$ (DAD) and 0.070 and $0.210 \mu \mathrm{g} . \mathrm{g}^{-1}$ (EC), respectively. 
Lastly, for kidney matrix, the LOD and LOQ values were 0.160 and $0.500 \mu \mathrm{g} \cdot \mathrm{g}^{-1}$ (DAD) and 0.040 and $0.110 \mu \mathrm{g} \cdot \mathrm{g}^{-1}$ (EC), respectively.

\subsubsection{Matrix effect}

The matrix effect was evaluated by comparing the slopes of the calibration curves obtained when processing standard 5\% perchloric acid solutions and deproteinized liver and kidney samples spiked with standards in the same concentrations. No significant difference was found by comparing $5 \%$ perchloric acid and liver. On the other hand, there is a statistically significant difference $(p<0.0001)$ between the 5\% perchloric acid standards and the $\alpha$ amanitin renal spiked samples, showing a significant matrix effect.

\subsubsection{Stability}

Stability of $\alpha$-amanitin was investigated using $5 \%$ perchloric acid, liver and kidney matrices. $\alpha$-Amanitin in all matrices was stable at room temperature and $4{ }^{\circ} \mathrm{C}$ over a period of $24 \mathrm{~h}$, with no significant degradation observed (Fig. 3). On the other hand, in the samples kept at room temperature, a degradation of $\alpha$-amanitin was observed over the period of 14 days. Significant degradation was already observed at 7 days being more pronounced at 14 days. Values of $\alpha$-amanitin declined to non-detectable concentrations at the 7th day at room temperature. In contrast, a slow degradation was observed in the case of $\alpha$-amanitin samples stored at $4{ }^{\circ} \mathrm{C}$. However, a significant degradation was observed at 7 days being more pronounced at 14 days. Excellent stability was obtained either at -20 and $-80^{\circ} \mathrm{C}$ as it can be seen in Fig. 3. No significant degradation of $\alpha$-amanitin in $5 \%$ perchloric acid, liver and kidney matrices was detected after storing the samples 14 days at -20 and $-80^{\circ} \mathrm{C}$. Moreover three freeze-thaw cycles did not cause any significant degradation in $5 \%$ perchloric acid and in both biological matrices analyzed. Overall the results show that $\alpha$-amanitin in tissue samples is stable during storage, extraction and chromatographic analysis. Moreover, we concluded that the samples can be safely stored at $-20^{\circ} \mathrm{C}$ and can be subjected to at least three cycles of freeze-thaw without significant degradation of the analyte.

\subsection{Method application}

The established HPLC method was applied to human plasma. Fig. 4 shows an EC chromatogram (A) and a chromatogram recorded at $305 \mathrm{~nm}$ (B) of blank plasma and plasma spiked to contain $5 \mu \mathrm{g}$ $\mathrm{mL}^{-1}$ of $\alpha$-amanitin. There were no endogenous interfering substances in the samples.

\section{5. $\alpha$-Amanitin quantification in kidney, liver and plasma after administration of $\alpha$-amanitin to rats}

The concentrations of $\alpha$-amanitin in rat plasma and tissues were determined after administration of a single intraperitoneal (10 or $21.4 \mathrm{mg} \mathrm{kg}^{-1}$ ) dose to Wistar rats. Representative EC chromatogram and chromatogram recorded at $305 \mathrm{~nm}$ of kidney and their respective spiking with $\alpha$-amanitin are show in Fig. 5 . Table 5 shows the values obtained by processing the plasma and tissues as indicated in section 2.4 and are expressed as $\mu \mathrm{g}$ of $\alpha$-amanitin per $g$ of protein in the tissues samples and expressed as $\mu \mathrm{g} \mathrm{mL}^{-1}$ in plasma samples. The highest overall concentrations in the tissues examined were in the following order: kidneys > liver. No detectable values were found in plasma. Peak identity was confirmed by spiking samples with $\alpha$-amanitin.

\section{Discussion}

Several methods are available in the literature for the analysis and quantification of $\alpha$-amanitin in different matrices, mainly mushrooms [11-15], plasma [20,28,29] and urine [16,21-22,29]
A

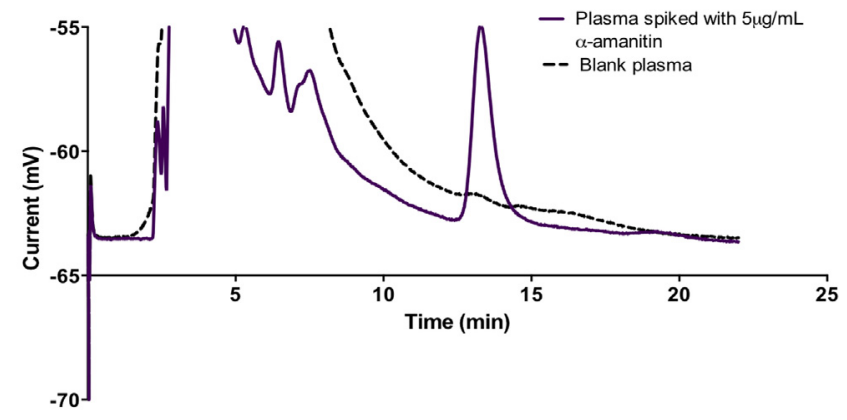

B

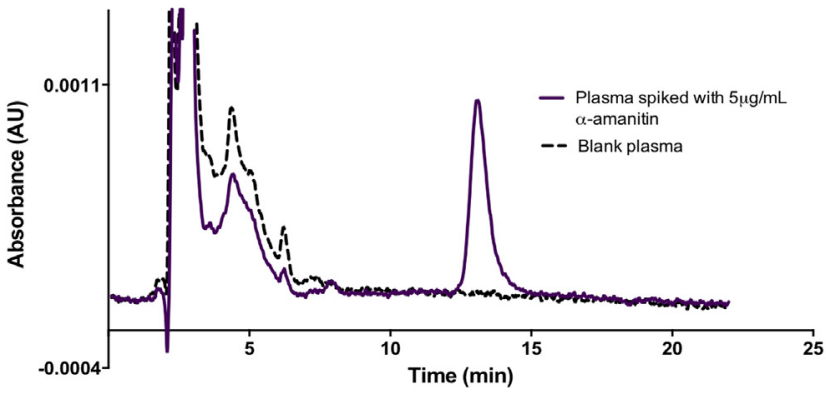

Fig. 4. Representative EC chromatograms of (A) blank plasma and plasma spiked to contain $5 \mu \mathrm{g} \mathrm{mL}^{-1}$ of $\alpha$-amanitin. Representative chromatograms recorded at $305 \mathrm{~nm}$ of (B) blank plasma and plasma spiked to contain $5 \mu \mathrm{g} \mathrm{mL} \mathrm{L}^{-1}$ of $\alpha$-amanitin.

Table 5

Quantification of $\alpha$-amanitin in real samples (plasma, liver, and kidney) from rats injected with $\alpha$-amanitin.

\begin{tabular}{|c|c|c|c|}
\hline & $\operatorname{Plasma}\left(\mu \mathrm{g} \mathrm{mL} \mathrm{L}^{-1}\right)$ & $\operatorname{Liver}\left(\mu \mathrm{g} \mathrm{g}^{-1}\right)$ & $\operatorname{Kidney}\left(\mu \mathrm{gg}^{-1}\right)$ \\
\hline \multicolumn{4}{|l|}{$305 \mathrm{~nm}$} \\
\hline Rat (10 $\left.\mathrm{mg} \mathrm{kg}^{-1} 4 \mathrm{~h}\right)$ & N.D. & 0.97 & 1.40 \\
\hline Rat (21.4 $\left.\mathrm{mg} \mathrm{kg}^{-1} 2 \mathrm{~h}\right)$ & N.D. & N.D. & 3.16 \\
\hline Rat (21.4 $\left.\mathrm{mg} \mathrm{kg}^{-1} 4 \mathrm{~h}\right)$ & N.D. & 0.71 & 26.58 \\
\hline \multicolumn{4}{|c|}{ Electrochemical detection } \\
\hline Rat $\left(10 \mathrm{mg} \mathrm{kg}^{-1} 4 \mathrm{~h}\right)$ & N.D. & 1.00 & 1.66 \\
\hline Rat (21.4 $\left.\mathrm{mg} \mathrm{kg}^{-1} 2 \mathrm{~h}\right)$ & N.D. & N.D. & 4.00 \\
\hline Rat (21.4 $\left.\mathrm{mg} \mathrm{kg}^{-1} 4 \mathrm{~h}\right)$ & N.D. & 0.80 & 33.74 \\
\hline
\end{tabular}

N.D.: not detectable.

(Table 1) due to the toxicological importance of this amatoxin. Research studies have been focused on the detection of $\alpha$-amanitin in body fluids for an early diagnosis of intoxications as to allow the rapid application of therapy [16,19,22]. However, presently the overall toxic mechanisms of $\alpha$-amanitin remain unclear, hindering the development of new and more effective antidotes, and relevant forensic studies on $\alpha$-amanitin are scarce. Improved knowledge of the toxicity mechanisms and the kinetics of this toxin will help the development of more efficient antidotes for A. phalloides poisoning. Moreover, recent findings suggest that $\alpha$-amanitin is emerging as an attractive new potent anticancer drug [10]. Therefore, the efficacy of $\alpha$-amanitin as an anticancer agent must be scientifically validated, through animal experiments that include pre-clinical pharmacokinetic and pharmacodynamic studies. To comprehensively characterize the mechanisms of toxicity, preclinical pharmacokinetics and efficacy of $\alpha$-amanitin as anticancer agent, a highly sensitive, accurate, and reproducible quantification method is required. To the best of our knowledge, there is only one HPLC-UV developed study for analysis of $\alpha$-amanitin in liver and 
A

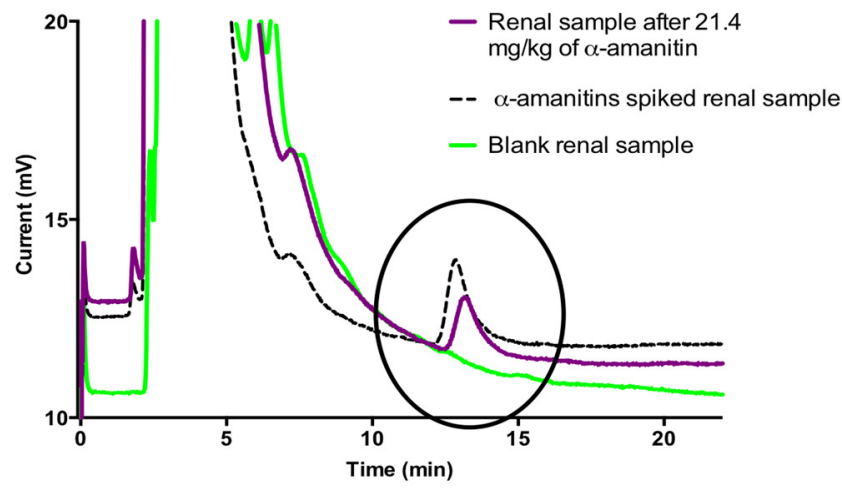

B

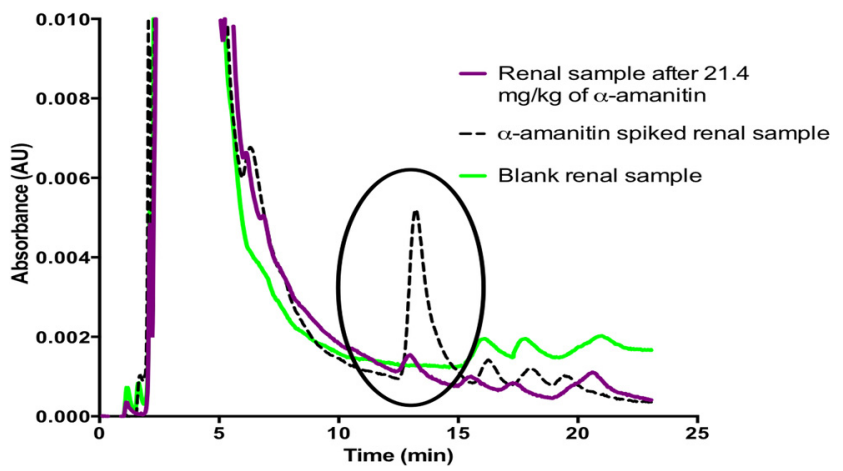

Fig. 5. (A) Representative EC chromatogram of rat kidney after an intraperitoneal administration of $21.4 \mathrm{mg} \mathrm{kg}^{-1}$ of $\alpha$-amanitin that was sacrificed $4 \mathrm{~h}$ later. The same sample was spiked with $\alpha$-amanitin. (B) Representative chromatogram recorded at $305 \mathrm{~nm}$ of rat kidney after an intraperitoneal administration of $21.4 \mathrm{mg} \mathrm{kg}^{-1}$ of $\alpha$ amanitin that was sacrificed $2 \mathrm{~h}$ later. The same sample was spiked with $\alpha$-amanitin.

kidney [29], whereas there is no study with EC detection for the analysis of $\alpha$-amanitin in this biological tissues. Therefore, it is evident that there is a lack of HPLC-EC-UV methods for the detection of $\alpha$-amanitin in liver and kidney, the target organs. The presence of a 6- hydroxytryptophan residue in the molecule of $\alpha$-amanitin suggested the possibility of detecting this compound through an EC detector operating in an oxidative mode $[22,28]$. Herein, an isocratic HPLC method using DAD and EC detectors was developed and validated for the quantitative measurement of $\alpha$-amanitin in rat liver and kidney tissues. This method has advantages over the previous methods by providing an extraction procedure of $\alpha$-amanitin from the tissue homogenates achieved by a unique deproteinization step using $5 \%$ perchloric acid followed by centrifugation, thus resulting in a simple, convenient and rapid separation of the analyte. Previously described extraction procedures of $\alpha$-amanitin in liver samples use organic solvents, methylene chloride and acetonitrile, being time-consuming and the resulting chromatograms are quite complex showing several interferences [19]. Deproteinization using 5\% perchloric acid can be performed on any biological sample and can be routinely applied in many laboratories all over the world. Herein, our procedure was also efficient with plasma samples, which indicates that this simple deproteinization step can be applied to other biological matrices. Moreover, clean chromatograms were obtained, thus improving the analysis. In our method, the buffer of the mobile phase was also optimized. The buffer capacity, the type of detectors used (DAD and EC), the stability of the solution, the solubility and the column were taken into account. Both LC-EC studies available so far, used a mobile phase composed of phosphate buffer and acetonitrile. One of the major problems with phosphate buffers is the precipitation of phosphates in the HPLC system. As an alternative, we used citrate as a buffer of the mobile phase. Citrate can be used in a wide range of $\mathrm{pH}(2.1<\mathrm{pH}<6.4)$ and provides low background noise, which is very important in electrochemical analysis [24,27]. The ratio of citrate: methanol (80:20): $0.46 \mathrm{mM}$ octanessulfonic acid and the $\mathrm{pH} 5.5$ were key to obtain good separation and resolution of the $\alpha$-amanitin peak. Moreover, the short run time of $22 \mathrm{~min}$ enables a large number of samples to be analyzed in a short period of time. Furthermore, the method was highly specific since liver, kidney and plasma samples analyzed did not exhibited chromatographic peaks corresponding to endogenous compounds co-eluting with the target analyte. Calibration curves over the entire range of concentrations were adequately described by $1 /$ concentration weighted quadratic regression of the peak-area ratios of $\alpha$-amanitin, with regression coefficient $r^{2}$ always greater than 0.994 in all analytical runs. This shows that our method was linear and a broad range of concentrations can be used. Extraction recovery at a concentrations ranging from 0.5 to $7.5 \mu \mathrm{g} \mathrm{mL} \mathrm{m}^{-1}$, results in an overall mean percent recovery of above $96 \%$. This recovery gives a great deal of confidence as this method can be applied into intoxicated humans, in terms of forensic analysis as well as to post-mortem tissues and therefore confirm the etiology of symptoms.

Considering the intra-assay variations (expressed as RSD), higher variability was found as the analyte levels were lower (Table 3) whereas for inter-assay variations (expressed as RSD), higher variability was found in the higher analyte levels (Table 3 ). Results show an overall RSD of $15.30 \%$, making the developed method precise. The LOD and LOQ values were obtained using two different criteria as to make it comparable to those methods found in the literature (Table 4). The values based on visual evaluation are slightly lower than the LOD and LOQ calculated from the linear regression parameters (Table 4). In previous reports, the LOD was about $10 \mathrm{ng} \mathrm{mL}^{-1}$ for urine by HPLC-UV [16], $2 \mathrm{ng}$ $\mathrm{mL}^{-1}$ (corresponding to a signal-to-noise ratio of $2: 1$ ) for plasma by HPLC-EC [28], although most of these methods are specific for a certain matrix. To the best of our knowledge, only three methodologies have been validated for $\alpha$-amanitin determination in the liver $[19,21,29]$. Jaeger et al. developed a HPLC-UV method for analysis of $\alpha$-amanitin in plasma, urine, feces, gastroduodenal fluid, kidney and liver [29]. The sample preparation involved a chemical step with deproteinization and organic solvent treatment, and a selective cleanup and concentration step on reversed-phase pre-packed cartridges. The LOD of this method was $5 \mathrm{ng} \mathrm{mL}^{-1}$ in liver and kidneys. However, since the content was presented as $\mathrm{ng} \mathrm{mL}^{-1}$ and the authors did not describe the method and the analytical procedure for the determination of LOD, we cannot compare it with our values. Leite et al. developed an analytical methodology of UPLC-MS/MS following liver sample preparation by protein precipitation with organic solvents, and solid phase extraction procedure and found a LOD based on signal-to-noise ratio $3: 1$ to be $10.9 \mathrm{ng} \mathrm{g}^{-1}$ [21], whereas our LOD was $15 \mathrm{ng} \mathrm{g}^{-1}$ (EC detection). Filigenzi et al. described a LC-MS/MS/MS method for the analysis of $\alpha$-amanitin in liver [19]. Liver was prepared by homogenization with aqueous acetonitrile and subsequent removal of acetonitrile was done using methylene chloride. The aqueous phase was then extracted using mixed-mode $\mathrm{C} 18$ /cation exchange solid phase extraction cartridges. The LOD in this method was $0.50 \mathrm{ng} \mathrm{g}^{-1}$. It is evident that the LODs in liver in the last two methods are lower than those described in our work. It is well known that MS and MS/MS/MS detectors offer highest sensitivity, however HPLC-MS instruments are not available in many laboratories. Moreover, our method provided a unique step of deproteinization for sample preparation, when compared to the multiple steps described in the mentioned works. The concentration of $\alpha$-amanitin in liver and kidney tissues poisoning cases analyzed by HPLC-UV show high variability $\left(0-1719 \mathrm{ng} \mathrm{g}^{-1}\right)$ [29], which indicates that our method is sensitive 
enough for the quantification of $\alpha$-amanitin in liver and kidney from suspected human intoxications.

The comparison between the two detectors (DAD and EC) shows that the LOD and LOQ for $\alpha$-amanitin could be improved through the use of an EC detector. Nevertheless, HPLC-EC instruments are not available in many laboratories. For that reason, validation using UV detector was made since it is a more common instrument all over the world. Moreover, it does not require a long period of stabilization as it happens with EC detector.

Evaluation of the matrix effect shows that there is a significant difference between the HPLC response for $\alpha$-amanitin in $5 \%$ perchloric acid and the response for the $\alpha$-amanitin in kidney matrix. This is probably due to residual components of the kidney matrix, thus demonstrating the importance of the study on equivalent matrices. On the other hand, no statistical difference was found between $5 \%$ perchloric acid and liver matrix.

The results of all stability tests indicate that $\alpha$-amanitin in 5\% perchloric acid and tissue samples was stable during sample storage, extraction and chromatographic analysis. Evaluation of more than one freeze-thaw cycle was performed, since samples may require multiple analysis. Three freeze thaw cycles also did not cause any significant degradation in all matrices when stored in acidic matrix. The tissue collection can be done after acidification since our data show that $\alpha$ - amanitin was stable at room temperature and $4{ }^{\circ} \mathrm{C}$ over a 24 hour period. No liquid nitrogen or urgent freezing seems to be required, making this method very practical and reliable in all laboratories and clinical settings.

As to prove the applicability of our method, we performed an in vivo study with different $\alpha$-amanitin doses and sacrifice times. After the intraperitoneal administration of a single dose of $\alpha$ amanitin (10 or $21.4 \mathrm{mg} / \mathrm{kg}$ ) to Wistar rats, the validated analytical method was successfully applied. In rats, there are no $\alpha$-amanitin pharmacokinetic data available at this point. Therefore, based on in vivo studies in murine models [9,30], we selected the 2 and $4 \mathrm{~h}$ post-administration periods to perform sample collection. The toxicokinetic of $\alpha$-amanitin has been studied in intoxicated humans and dogs and shows to have a short half-life (it is totally eliminated from the blood after $41.02 \mathrm{~min}$ ), being widely distributed to target tissues (liver and kidney). Our method was able to detect $\alpha$-amanitin in several samples. The short plasma half-time of $\alpha$ amanitin was confirmed, as no analyte was found in plasma. Our results show higher levels of total $\alpha$-amanitin in kidney than in liver. These differences may be explained by pharmacokinetic proprieties of $\alpha$-amanitin in this animal model, which mainly accumulates in the kidney.

Of interest, this method was also successfully applied to quantify $\alpha$-amanitin in human plasma since there were no endogenous substances co-eluting with the peak of interest. Taking this under consideration, we suggest that this method can be used for early diagnosis of $A$. phalloides poisoning, tissues analysis and other pharmacokinetic studies. In fact, this method is a suitable tool to support in vivo toxicokinetic studies designed to elucidate the mechanisms of toxicity of $\alpha$-amanitin, being able to help in the development of novel and potent antidotes against amatoxin's poisoning.

\section{Conclusion}

A selective and sensitive HPLC method using DAD and EC detectors has been developed and validated for the quantitative measurement of $\alpha$-amanitin in 5\% perchloric acid, rat liver and kidney. The extraction of $\alpha$-amanitin from tissue homogenates was achieved by a simple deproteinization step with a high recovery of the analyte. Validation was carried out by the evaluation of the most relevant parameters for checking the quality of the method. The method proved to be linear in the concentration range studied, as well as it showed to selective, accurate, precise and sensitive. All stability tests indicated that $\alpha$-amanitin was stable during sample storage, extraction, and chromatographic analysis. Moreover, this method was successfully applied to real samples, after $\alpha$ - amanitin administration to Wistar rats. Taken together, these characteristics combined with a short chromatographic run time of $22 \mathrm{~min}$ allow this method to be easily applied for the determination of $\alpha$-amanitin in liver and kidney and other biological samples. This method provides a convenient tool for the future toxicological and clinical studies involving $\alpha$ - amanitin.

\section{Acknowledgments}

This work received financial support from the European Union (FEDER funds through COMPETE) and National Funds (FCT, Fundação para a Ciência e Tecnologia) through project PestC/EQB/LA0006/2013.

Juliana Garcia and Vera Marisa Costa thank FCT - Foundation for Science and Technology - for their PhD grant (SFRH/BD/74979/ 2010 ) and Post-doc grant (SFRH/BPD/63746/2009), respectively.

\section{References}

[1] J. Vetter, Toxins of Amanita phalloides, Toxicon 36 (1998) 13-24

[2] A.W. Hayes, Principles and Methods of Toxicology, Fifth Edition, Taylor \& Francis 2008.

[3] T.J. Lindell, F. Weinberg, P.W. Morris, R.G. Roeder, W.J. Rutter, Specific inhibition of nuclear RNA polymerase II by alpha-amanitin, Science 170 (1970) 447-449.

[4] A. Zheleva, A. Tolekova, M. Zhelev, V. Uzunova, M. Platikanova, V. Gadzheva, Free radical reactions might contribute to severe alpha amanitin hepatotoxicity-a hypothesis, Med. Hypotheses 69 (2007) 361-367.

[5] F. Enjalbert, S. Rapior, J. Nouguier-Soule, S. Guillon, N. Amouroux, C. Cabot, Treatment of amatoxin poisoning: 20-year retrospective analysis, J. Toxicol. Clin. Toxicol. 40 (2002) 715-757.

[6] J. Garcia, A.T.P. Carvalho, D.F.A.R. Dourado, P. Baptista, M. de Lourdes Bastos, F. Carvalho, New in silico insights into the inhibition of RNAP II by $\alpha$-amanitin and the protective effect mediated by effective antidotes, J. Mol. Graphics Modell. 51 (2014) 120-127.

[7] J. Magdalan, A. Ostrowska, A. Piotrowska, A. Gomułkiewicz, A. Szelag, P. Dzięgiel, Comparative antidotal efficacy of benzylpenicillin, ceftazidime and rifamycin in cultured human hepatocytes intoxicated with $\alpha$-amanitin, Arch. Toxicol. 83 (2009) 1091-1096.

[8] P. Poucheret, F. Fons, J.C. Dore, D. Michelot, S. Rapior, Amatoxin poisoning treatment decision-making: pharmaco-therapeutic clinical strategy assessment using multidimensional multivariate statistic analysis, Toxicon 55 (2010) 1338-1345.

[9] T.C. Tong, M. Hernandez, W.H. Richardson, 3rd, D.P. Betten, M. Favata, R.H. Riffenburgh, R.F. Clark, D.A. Tanen, Comparative treatment of alpha-amanitin poisoning with $\mathrm{N}$-acetylcysteine, benzylpenicillin, cimetidine, thioctic acid, and silybin in a murine model, Ann. Emerg. Med. 50 (2007) 282-288.

[10] G. Moldenhauer, A.V. Salnikov, S. Luttgau, I. Herr, J. Anderl, H. Faulstich, Therapeutic potential of amanitin- conjugated anti-epithelial cell adhesion molecule monoclonal antibody against pancreatic carcinoma, J. Natl. Cancer Inst. 104 (2012) 622-634.

[11] F. Enjalbert, G. Cassanas, G. Guinchard, J.P. Chaumont, Toxin composition of Amanita phalloides tissues in relation to the collection site, Mycologia 88 (1996) 909-921.

[12] F. Enjalbert, G. Cassanas, S. Rapior, C. Renault, J.P. Chaumont, Amatoxins in wood-rotting Galerina marginata, Mycologia 96 (2004) 720-729.

[13] F. Enjalbert, G. Cassanas, S.L. Salhi, C. Guinchard, J.-P. Chaumont, Distribution of the amatoxins and phallotoxins in Amanita phalloides. Influence of the tissues and the collection site, C. R. Acad. Sci. III 322 (1999) 855-862.

[14] F. Enjalbert, C. Gallion, F. Jehl, H. Monteil, Toxin content, phallotoxin and amatoxin composition of Amanita phalloides tissues, Toxicon 31 (1993) 803-807.

[15] F. Enjalbert, C. Gallion, F. Jehl, H. Monteil, H. Faulstich, Simultaneous assay for amatoxins and phallotoxins in Amanita phalloides Fr. by high-performance liquid chromatography, J. Chromatogr. A. 598 (1992) 227-236.

[16] F. Jehl, C. Gallion, P. Birckel, A. Jaeger, F. Flesch, R. Minck, Determination of alpha-amanitin and beta-amanitin in human biological fluids by high-performance liquid chromatography, Anal. Biochem. 149 (1985) 35-42.

[17] E. Kaya, M.G. Surmen, K.O. Yaykasli, S. Karahan, M. Oktay, H. Turan, S. Colakoglu, H. Erdem, Dermal absorption and toxicity of alpha amanitin in mice, Cutaneous Ocul. Toxicol. 14 (2013) 14.

[18] W.C. Chung, S.C. Tso, S.T. Sze, Separation of polar mushroom toxins by mixed-mode hydrophilic and ionic interaction liquid 
chromatography-electrospray ionization-mass spectrometry, J. Chromatogr. Sci. 45 (2007) 104-111.

[19] M.S. Filigenzi, R.H. Poppenga, A.K. Tiwary, B. Puschner, Determination of alpha-amanitin in serum and liver by multistage linear ion trap mass spectrometry, J. Agric. Food Chem. 55 (2007) 2784-2790.

[20] M. Tanahashi, R. Kaneko, Y. Hirata, M. Hamajima, T. Arinobu, T. Ogawa, A. Ishii, Simple analysis of $\alpha$-amanitin and $\beta$-amanitin in human plasma by liquid chromatography-mass spectrometry, Forensic Toxicol. 28 (2010) 110-114.

[21] M. Leite, A. Freitas, A.M. Azul, J. Barbosa, S. Costa, F. Ramos, Development, optimization and application of an analytical methodology by ultra performance liquid chromatography-tandem mass spectrometry for determination of amanitins in urine and liver samples, Anal. Chim. Acta 799 (2013) 77-87.

[22] C. Defendenti, E. Bonacina, M. Mauroni, L. Gelosa, Validation of a high performance liquid chromatographic method for alpha amanitin determination in urine, Forensic Sci. Int. 92 (1998) 59-68.

[23] R. Singh, HPLC method development and validation- an overview, J. Adv. Pharm. Educ. Res. 4 (2013) 26-33.

[24] L.R. Snyder, J.J. Kirkland, J.L. Glajch, Practical HPLC Method Development, Wiley, 2012.

[25] ICH, Validation of Analytical Procedures_Methodology, The International Conference on Harmonisation of Technical Requirements for registration of Pharmaceuticals for Human use, 1996.
[26] O.H. Lowry, N.J. Rosebrough, A.L. Farr, R.J. Randall, Protein measurement with the Folin phenol reagent, J. Biol. Chem. 193 (1951) 265-275.

[27] V.M. Costa, R. Silva, L.M. Ferreira, P.S. Branco, F. Carvalho, M.L. Bastos, R.A. Carvalho, M. Carvalho, F. Remião, Oxidation process of adrenaline in freshly isolated rat cardiomyocytes: formation of adrenochrome, quinoproteins, and GSH adduct, Chem. Res. Toxicol. 20 (2007) 1183-1191.

[28] F. Tagliaro, G. Schiavon, G. Bontempelli, G. Carli, M. Marigo, Improved high-performance liquid chromatographic determination with amperometric detection of $\alpha$-amanitin in human plasma based on its voltammetric study, J. Chromatogr. B. Biomed. Sci. Appl. 563 (1991) 299-311.

[29] A. Jaeger, F. Jehl, F. Flesch, P. Sauder, J. Kopferschmitt, Kinetics of amatoxins in human poisoning: therapeutic implications, J. Toxicol. Clin. Toxicol. 31 (1993) 63-80.

[30] S.M. Schneider, E.A. Michelson, G. Vanscoy, Failure of N-acetylcysteine to reduce alpha amanitin toxicity, J. Appl. Toxicol. 12 (1992) 141-142.

[31] X. Zuo, Z. Zhou, L. Zhou, Y. Tang, M. Cao, Determination of $\alpha$-amanitin in human serum by solid-phase extracton coupled with HPLC-UV, LCGC N. Am. 29 (2011) 672

[32] H.H. Maurer, C.J. Schmitt, A.A. Weber, T. Kraemer, Validated electrospray liquid chromatographic-mass spectrometric assay for the determination of the mushroom toxins alpha- and beta-amanitin in urine after immunoaffinity extraction, J. Chromatogr. B. Biomed. Sci. Appl. 748 (2000) 125-135. 